\title{
САМООЦЕНКА ЗДОРОВЬЯ СТУДЕНТОВ В УСЛОВИЯХ ДИСТАНЦИОННОГО ОБУЧЕНИЯ ПЕРИОДА САМОИЗОЛЯЦИИ
}

\section{SELF-ASSESSMENT OF STUDENTS' HEALTH IN THE CONDITIONS OF DISTANCE LEARNING DURING THE PERIOD OF SELF-ISOLATION}

A. Starostina

A. Nikulin

I. Kustova

Summary: The transition of students to distance learning during the period of self-isolation attracted close attention not only of the public, but also of teachers, in particular. Reduced motor activity, violations of the daily routine, nutrition, sleep and rest led to a deterioration in the physical and psychological health of students. As a result of the survey, having found out the self-assessment of students ' health, we proposed methodological recommendations aimed at maintaining a healthpreserving environment during the period of self-isolation.

Keywords: health, health care, healthy lifestyle, distance learning in the period of self-isolation.

\author{
Старостина Анна Владимировна \\ К.п.н., дочент, Вологодский государственный \\ университет \\ annastart1@mail.ru \\ Никулин Александр Валентинович \\ К.п.н., дочент, Вологодский государственный \\ университет \\ nikulinav74@yandex.ru \\ Кустова Ирина Александровна \\ К.п.н., дочент, Вологодский государственный \\ университет \\ kustovaia35@ya.ru
}

Аннотация: Переход обучающихся на дистанционное обучение в период самоизоляции привлек пристальное внимание не только общественности, но и педагогов, в частности. Снижение двигательной активности, нарушения режима дня, питания, сна и отдыха повлекли за собой ухудшение физического и психологического здоровья обучающихся. В результате анкетирования, выяснив самооценку здоровья студентов, нами предложены методические рекомендации, направленные на поддержание здоровьесберегающей среды в период самоизоляции.

Ключевые слова: здоровье, здоровьесбережение, здоровый образа жизни, дистанционное обучение в период самоизоляции.

пункты стали не многолюдны.

Соблюдая необходимые меры предосторожности от вирусного заражения, студенты вынуждены были сменить свой привычный образ жизни, значительную часть дня предоставляя учебной работе за компьютером в сидячем положении, сократить суточную двигательную активность, общение с друзьями и другими сокурсниками. Поддержание спортивной формы, уровня двигательной активности и здоровья студентов, в целом, в сложившейся ситуации обернулось реальной проблемой. Так как затянувшееся пребывание дома в течение длительного периода времени серьезно осложняло процесс сохранения здоровья обучающихся.

Цель исследования - изучить самооценку здоровья студентов в период дистанционного обучения и самоизоляции для повышения эффективности образовательного процесса. Задачи исследования: 1) выяснить условия дистанционного обучения студентов в сложившейся ситуации; 2) рассмотреть влияние дистанционного обучения в период самоизоляции на здоровье с помощью самооценки обучающихся; 3) проанализировать результаты исследования и разработать методические рекомендации здоровьесбережения студентов в период самоизоляции. 
Необходимость изучения мнения студентов потребовала использования следующих методов исследования: теоретический анализ состояния проблемы, наблюдения, экспериментальная работа, обобщение авторского опыта работы, анкетирование.

В анкетировании приняли участие 152 обучающихся технических специальностей 1-4 курсов очной формы обучения Вологодского государственного университета, из которых 67, 1\% составляют девушки, 32, 9\% - юноши.

Анкета содержала вопросы о соблюдении студентами здорового образа жизни, влиянии на организм человека условий дистанционного обучения, самочувствии обучающихся и его изменениях в период самоизоляции.

Надо подчеркнуть, что быстрый переход от очной формы к дистанционному обучению студенты восприняли достаточно благосклонно и с пониманием. Проблемы стали проявляться позже.

Как выяснилось, техническая оснащенность данной формы обучения оставляла желать лучшего. Лишь 21,1\% обучающихся имели дома компьютеры, 51,3\% обучающихся использовали телефоны, 9,2\% обучающихся не имели подобного оборудования вообще и 18,4\% обучающихся были вынуждены приобрести какой-либо вид технических средств для обучения в домашних условиях.

Надо отметить, что работа на портале вуза и связь студент-преподаватель наладились не сразу из-за сбоев центров связи города, чрезмерной перегрузки техники университета и недостаточного объема сохранения информации и возможностей технических средств обучающихся. В дальнейшем, первая проблема была быстро устранена. Вторая - существует и по сей день. Многие студенты, находясь дома в отдаленных населенных пунктах, где сотовая связь и интернет отсутствовали или работали с перебоями, оставались недоступными для общения и длительное время отсутствовали в образовательном пространстве.

В режиме самоизоляции резко сократилась двигательная активность молодежи. Передвижения до университета, из аудитории в аудиторию, между зданиями и обратно домой прекратились. Лекционные занятия и выполнение домашних заданий в сидячем положении стали занимать большую часть дня студентов. Лишь 40,8 \% респондентов старались выполнять прежний суточный объем двигательной активности.

На вопрос анкеты «Сколько времени в день в среднем вы двигаетесь в условиях самоизоляции, включая пешие переходы, походы в магазины, занятия физкультурой, уборку дома и пр.?» 9,2\% респондентов ответили более 3 часов в день, 11,8\% респондентов - менее 1 часа, остальные 79,1\% респондентов - 2-3 часа в день.

Ответы респондентов на вопрос «Является ли ваша двигательная активность для вас достаточной?» следующие: положительные - у 36,8\% респондентов; отрицательные - у 63,2\% респондентов.

Негативная нагрузка на глаза, позвоночник, мышечную систему организма в сидячем положении за компьютером, особенно в работе на телефоне, значительно увеличилась. Составление схем, графиков, таблиц, текстовых заданий отнимает более длительный промежуток времени при работе с телефоном. Лишь 19,7 \% респондентов считали объем работы за компьютером в течение дня оптимальным. Остальные $80,3 \%$ респондентов - чрезмерным.

Наличие в интернете различных электронных библиотек, учебных сайтов, научных конференций, специальной литературы во многом облегчает поиск необходимой полезной информации, но их изучение, ранжирование, использование требует затраты большого количества времени в положении сидя за компьютером $[3$, с. 86].

Далее выяснилось, что на вопрос «Сколько времени вы проводите, используя различные гаджеты для дистанционного обучения?» респонденты отметили следующее. 1-2 часа в день - 9,2\% респондентов, 3-4 часа в день - 17,1\% респондентов, 5-6 часов в день - 25,0\% респондентов, 8 часов и более - 15,8\% респондентов, постоянно - 32,9\% респондентов. Студенты выполняли большой объем учебных заданий, что требовало длительной затраты времени, тем самым получая чрезмерную нагрузку на глаза, позвоночник, мышечную и опорно-двигательную системы всего организма, нанося существенный вред своему здоровью.

В свою очередь, такая учебная работа повлекла за собой нарушение режима сна, отдыха, питания, всего привычного распорядка дня обучающихся. Так, 56,6\% обучающихся считали, что их образ жизни в период самоизоляции претерпел незначительные перемены, а 43,4\% обучающихся указывали на существенные изменения в режиме дня. В последствии, 86,8\% обучающихся высказали недовольство и хотели бы вернуться как можно скорее к обычному образу жизни. Лишь 13,2\% обучающихся полностью приспособились и комфортно себя чувствовали в условиях самоизоляции. При этом студенты $(97,4 \%)$ были убеждены в том, что такой образ жизни оказывает большое отрицательное влияние на здоровье и лишь 2,6\% студентов убеждены в обратном.

Анкетирование показало, что учебная нагрузка, занимающая большую часть дня, привела к нарушению 
режима питания. Немногим более половины, 55,3\% респондентов, уверяли, что продолжали своевременно и рационально питаться. Но 44,7\% респондентов не успевали готовить и принимать пищу в положенный срок. 60,5\% респондентов принимали пищу 2-3 раза в день, 30,3\% респондентов - 4 раза в день, более 4 раз - 9,2\% респондентов.

Студенты (31,6\% респондентов) констатировали, что в результате неправильного питания их вес тела повысился за период самоизоляции. У $42,1 \%$ респондентов вес тела остался прежним, 26,3\% респондентов не следили за своей массой тела и затруднялись с ответом.

В период самоизоляции 63,2\% студентов испытывали психологический дискомфорт, который возникает в следствие недостатка общения с друзьями и сверстниками, необходимой смены домашней обстановки, привычного передвижения в общественных местах. Отмечено, что 43,4 \% студентов были подвержены состоянию психологического неблагополучия. Лишь 36,8 \% студентов не испытывали каких-либо изменений в своем психологическом состоянии. Также, 21,1\% студентов сохранили свою подверженность вредным привычкам.

По мнению респондентов, меньше половины 42,1\% обучающихся соблюдали режим сна и отдыха. 57,9\% обучающихся нарушали данный фактор образа жизни и, как следствие, малая продолжительность сна отрицательно влияла на общую работоспособность и учебный настрой студентов. Тем самым вызывая вялость, сонливость и быструю утомляемость организма в течение дня. 38,2\% обучающихся высказали неудовлетворенность тревожным и некрепким сном. У 23,7\% обучающихся ночной сон занимал менее 7 часов. Беспорядочный сон испытывали $18,4 \%$ обучающихся.

В анкетах респонденты указали на неполноценный отдых (52,6\% обучающихся). 47,4\% обучающихся утверждали, что времени на оптимальный полноценный отдых недостаточно. Причем, активный отдых предпочитали 21,1\% респондентов, пассивный - 5,2\% респондентов и смешанный - 73,7\% респондентов.

Как известно, систематические занятия физическими упражнениями повышают активность обменных процессов, поддерживают на высоком уровне механизмы, которые осуществляют в организме обмен веществ и энергии. У студентов, регулярно занимающихся физическими упражнениями, значительно повышается потенциал всех систем и органов, что благотворно влияет на его физическое развитие и здоровье в целом [2, с. 120].

В ходе исследования, мы выяснили, что лишь 42,8\% студентов выполняли регулярно все задания преподавателя физической культуры, 26,8\% студентов выполняли не систематически и 30,4\% студентов признались, что по тем или иным причинам не выполняли их вообще. Длительность занятий физической культурой составляла менее 1 часа у 42,1\% студентов, 1 час - 39,5\% студентов, 2 часа - 14,5\% студентов и более 2 -х часов - 3,9\% студентов.

Отвечая на вопросы анкеты, 78,4\% обучающихся утверждали, что справлялись с физической нагрузкой, заданной преподавателем, 21,6\% обучающихся - не справлялись, так как занимались не регулярно и имели пропуски занятий.

Помимо дистанционной учебной работы по физической культуре в вузе, по утверждению обучающихся, $65,8 \%$ респондентов занимались самостоятельно какими-либо видами физических упражнений, 34,2\% респондентов не утруждали себя подобными занятиями или не успевали в течение дня уделить время дополнительным физическим упражнениям.

По мнению студентов, 19,7\% респондентов выполняли физкультминутки или физкультпаузы в течение рабочего дня, направленные на переключение деятельности, снятия утомления с глаз, мышц шеи и позвоночника. 48,7\% студентов прибегали к таким занятиям эпизодически. И 31,6\% студентов не использовали их в своей работе. Но почти все студенты убеждены, что очень важно для здоровья делать физкультперерывы $(97,4 \%)$. Но есть и такие студенты, которые в них не нуждаются сознательно (2,6\%).

Учитывая состояние здоровья в течение рабочего дня, студенты показали, что испытывали чрезмерную утомляемость глаз 35,5\% респондентов, боль в коленях $19,7 \%$ респондентов, немела спина у $28,9 \%$ респондентов, головные боли испытывали $31,6 \%$ респондентов, переутомление всех частей тела - 53,9\% респондентов. Лишь 11,8\% обучающихся не имели жалоб и указывали на хорошее самочувствие.

Респонденты утверждали, что дистанционное обучение отрицательно влияет на здоровье (64,5\%), не влияет - 27,6\% респондентов. И пользу данного обучения обнаружили лишь 7,9\% респондентов.

В общем, дистанционная форма обучения одобрялась 34,2\% студентами. Высказались против нее 65,8\% респондентов. 61,8\% студентов считают период самоизоляции приемлемым для улучшения своего здоровья, а 32,2\% респондентов убеждены в обратном.

В итоге, при выборе формы обучения, на данный момент, за дистанционную форму обучения высказались лишь 18,4\% студентов, очную форму обучения предпочло большинство $81,6 \%$ студентов. 
Таким образом, результаты анкетирования показали, что в условиях дистанционного обучения более остро обозначились проблемы здоровьесбережения, так как большую часть дня студенты проводили, сидя у компьютера, слушая лекции и справляясь с учебными заданиями, что привело к чрезмерной утомляемости и снижению общей работоспособности в конце дня. Студенты отмечали головные боли, усталость глаз и боли в спине, онемение нижних конечностей в результате долгой сидячей работы в однообразном положении тела.

Как показало исследование, претерпел изменения не в лучшую сторону режим дня, питания, сна и отдыха. Дефицит общения и отстраненность в социальном пространстве привели к отрицательным изменениям психологического здоровья обучающихся.

По мнению обучающихся, их уровень двигательной активности являлся недостаточным в период самоизоляции. Учебные задания по физической культуре выполнялись студентами не регулярно и не в полном объеме. Недостаток физической активности студенты пытались компенсировать самостоятельными физическими упражнениями, прогулками на свежем воздухе, уборкой квартиры. Но таких желающих оказалось лишь пятая часть от общего числа респондентов.

Видеоотчеты обучающихся на протяжении дистанционного обучения показали, что домашние условия у большинства респондентов не позволяют проводить занятия физической культурой в полном объеме и с достаточным разнообразием упражнений. Самый доступный спортивный инвентарь, такой как скакалка, гантели, гимнастические коврик и палка, не имели в наличии большинство студентов.

Следовательно, к факторам, оказывающим негативное воздействие на здоровье обучающихся, относятся: гиподинамия; стесненная поза, сидячее положение в течение длительного времени; утомление глаз, нагрузка на зрение; перегрузка позвоночника; стресс при обработке учебной информации.

По нашему мнению, важным аспектом формирования здоровьесберегающей среды дистанционного обучения является психологическая комфортность обучающихся. Она достигается созданием позитивной мотивации на работу, доброжелательным контекстом общения со стороны преподавателя в групповых и личных чатах, педагогической поддержкой в ситуациях возникновения трудностей в обучении, своевременной эмоциональной поддержкой обучающегося посредством обеспечения положительных эмоциональных взаимоотношений между всеми участниками образовательного процесса.

Для предупреждения снижения работоспособности, развития переутомления, обязательными мероприятиями являются:

- обеспечение оптимальности светового и воздушно-теплового режимов в помещении;

- проведение проветривания комнаты, где находится рабочее место обучающегося, в перерывах между занятиями;

- проведение влажной уборки комнаты;

- выполнение утренней зарядки, самостоятельных физических упражнений в течение дня;

- осуществление дневной и вечерней прогулки на свежем воздухе;

- проведение гимнастики для глаз, физкультминуток (динамических пауз) в течение учебного занятия;

- проведение по окончании занятия физкультпауз в целях профилактики утомления глаз, шейного отдела, нарушения осанки и др.

В связи с выше сказанным возникает потребность в поиске новых средств для привлечения молодежи к самостоятельным занятиям физической культурой с целью предупреждения и профилактики различных недомоганий, возникающих в учебном процессе. Учитывая многолетний педагогический опыт, одним из наиболее эффективных и доступных средств поддержания здоровья студентов являются физкультпаузы в течение дня.

Физкультпауза - способ снятия усталости и напряжения в стрессовых ситуациях и больших эмоциональных перегрузках во время дистанционного учебного процесса. Мы представляем примерный комплекс упражнений для проведения физкульпауз в домашних условиях.

Примерный комплекс упражнений физкульпаузы.

• И.п. - сидя, поставить локти на стол, опереться лобной частью головы на ладони рук.

1-6. - надавить головой на кисти рук, удерживая напряжение;

7-8. - ослабить напряжение, оторвав голову от ладоней.

• И.п. - сидя, откинувшись на спинку стула, скрестить ладони на затылочной части головы.

1-6. - наклон головы назад, преодолевая сопротивление кистей;

7-8- и.п.

- И.п. - сидя или о.с. Прикрыть веки, крепко зажмурить глаза, затем открыть.

- И.п. - сидя или о.с. Поднять глаза кверху, сделать ими круговые движения по часовой стрелке, затем против часовой стрелки.

- И.п. - сидя или о.с. Направить взгляд вверх, вниз, вправо, влево.

- И.п. - стойка, руки на поясе, спина прямая.

1-2. - повернуть голову вправо, посмотреть на локоть 
правой руки;

3-4. - и.п.;

5-6. - повернуть голову влево, посмотреть на локоть левой руки.

- И.п. - стойка, руки за головой, локти вперед.

1-2. - развести локти в стороны, прогнуться;

3-4. - и.п.

- И.п. - стойка, опереться руками на спинку стула.

1-3. - 3 наклона вперед, прогибаясь в поясничном отделе;

4. - и.п.

- И.п. - стойка, руки на поясе.

1. - полуприсед, руки вперед;

2. - и.п.

3. - присед, руки вперед;

4. - и.п.

- И.п. - стойка, руки на поясе.

1-3. - 3 наклона вперед, коснуться руками пола;

4. - и.п.

- И.п. - стойка, руки к плечам.

1-3. - 3 наклона вправо, руки вверх;

4. - и.п.;

5-7. - 3 наклона влево, руки вверх;

8. - и.п.

-И.п. - о.с.

1. - руки вверх, правую ногу назад на носок, прогнуться, посмотреть на руки;

2. - и.п.;

3. - руки вверх, левую ногу назад на носок, прогнуться, посмотреть на руки;

4. - и.п.

• И.п. - о.с. Подскоки с ноги на ногу.

Данный комплекс упражнений не требует большого пространства и достаточно прост для выполнения. 2-3 физкульпаузы в течение дня обеспечивают активный отдых, переключают внимание с одного вида деятельности на другой, помогают ликвидировать застойные явления в органах и системах, улучшают обменные процессы, способствуют повышению внимания и физической активности обучающихся.

Создание здоровой образовательной среды в период самоизоляции имеет огромное значение для роста работоспособности, устойчивого иммунитета и поддержание здоровья обучающихся, что повышает эффективность всего учебного процесса в целом. Сохранение и укрепление здоровья во многом зависит, прежде всего, от самого обучающегося и, конечно, педагогов высшей школы, призванных научить студентов использовать полученные знания в повседневной жизни.

Последовательное развитие потребности в систематических занятиях физическими упражнениями - одна из важных задач преподавателя физкультуры, которую необходимо решать с первых этапов приобщения студентов к физкультурной деятельности на основе содержательных мотивов занятий, сообщения знаний, необходимых для самостоятельного использования средств физического воспитания, развития активности, инициативности, самостоятельности [4, с. 162].

Для решения данной проблемы, следует учитывать индивидуальные возможности и предпочтения студентов в выборе вида физкультурно-оздоровительной деятельности, необходимо формировать у студентов осознанную потребность в физической культуре, здоровом образе жизни и сохранении собственного здоровья, использовать потенциал всех субъектов в образовательном пространстве вуза [1, с. 85]

\section{ЛИТЕРАТУРА}

1. Никулин А.В., Бушманова 0.И., Старостина А.В. К вопросу изучения отношения студентов к занятиям физической культурой и спортом на примере Вологодского государственного университета // Современная наука: актуальные проблемы теории и практики. Серия «Гуманитарные науки». - 2020. № 2. - C. 81-85.

2. Старостина А.В. Изучение проблемы отношения студентов к физической культуре / А.В. Старостина // Актуальные вопросы образования в сфере физической культуры и спорта: сборник научных трудов. Министерство науки и высшего образования Российской Федерации, Вологодский государственный университет - Вологда: ВоГУ, 2019. - Вып. 8. - С. 120-125.

3. Старостина А.В. Физическая активность в период дистанционного обучения студентов / А.В. Старостина, А.Э. Жданова // Физическое воспитание в условиях современного образовательного процесса: сб. материалов национальной науч.-практ. конф. - Шуя: Шуйский филиал ИвГУ, 2020. - С. 85-88.

4. Старостина А.В. Формирование ценностного отношения к здоровью студентов / А.В. Старостина // Физическое воспитание, спорт, физическая реабилитация и рекреация: проблемы и перспективы развития: материалы 5 Междунар. науч.-практ. конф.; Сиб. гос. аэрокосм. ун-т. - Красноярск, 2015. C. 260-264.

(с Старостина Анна Владимировна (annastart1@mail.ru), Никулин Александр Валентинович (nikulinav74@yandex.ru), Кустова Ирина Александровна (kustovaia35@ya.ru).

Журнал «Современная наука: актуальные проблемы теории и практики» 